\title{
Blockade of IGF-IR exerts anticancer effects in hepatocellular carcinoma
}

\author{
WEI-FENG YAO ${ }^{1}$, JUN-WEI LIU ${ }^{2}$, GUO-LIANG SHENG ${ }^{2}$ and DONG-SHENG HUANG ${ }^{1,2}$ \\ ${ }^{1}$ Department of General Surgery, Key Laboratory of Biotherapy of Zhejiang Province, Xiasha Hospital; \\ ${ }^{2}$ Sir Run Run Shaw Affiliated Hospital, Zhejiang University School of Medicine, Hangzhou 310016, P.R. China
}

Received December 14, 2010; Accepted April 20, 2011

DOI: $10.3892 / \mathrm{mmr} .2011 .486$

\begin{abstract}
Hepatocellular carcinoma (HCC) is one of the most common cancers worldwide, and is characterized by a high degree of malignancy and a low survival rate. Most HCCs express insulin-like growth factors and their receptors (IGF-IR), which mediate signaling, promote survival and invasion, and prevent apoptosis. Thus, they may be potential targets for the treatment of HCCs. In the present study, the potential therapeutic effect of Tyrphostin AG1024 in HCC was examined. After treatment with various concentrations of AG1024 (one selective inhibitor of IGF-IR), AG1024 not only dose-dependently inhibited the proliferation of HCC cells and induced apoptosis, but also markedly inhibited invasion ability. Expression of proteins detected by Western blot analysis revealed that AG1024 dose-dependently increased the expression of cytochrome $\mathrm{C}$, while procaspase-3 and phospho-ERK were down-regulated. Thus, IGF-IR inhibition may be a promising novel approach to the treatment of HCC.
\end{abstract}

\section{Introduction}

The imbalance between proliferation and apoptosis may result from the loss of coordinated response to growth factors and cytokines (1). Dysregulation of cell apoptosis and proliferation may result in malignancy. To prevent programmed cell death, tumor cells frequently evolve to express growth factors that promote survival signaling pathways, thereby inhibiting apoptosis. Among these, the insulin-like growth factors (IGF-I and IGF-II) are suitable candidates.

The interaction of IGF-I and IGF-II with type-I IGF receptor (IGF-IR) plays an important role in the proliferation of tumor cells of many types $(2,3)$ and in the prevention of

Correspondence to: Dr Dong-Sheng Huang, Department of General Surgery, Key Laboratory of Biotherapy of Zhejiang Province, Xiasha Hospital, and Sir Run Run Shaw Affiliated Hospital, Zhejiang University School of Medicine, Hangzhou 310016, P.R. China

E-mail: joe2118@zju.edu.cn; dshuang@zju.edu.cn

Key words: insulin-like growth factor receptor inhibitor, hepatocellular carcinoma, apoptosis apoptosis $(4,5)$. Recent studies on hepatocellular carcinoma (HCC) cell lines and a transgenic mouse model revealed that IGFs as survival factors were capable of inhibiting the apoptosis of tumor cells.

Studies in vitro and in vivo have revealed that interfering with signaling via IGF-IR has an antitumor effect, including the applications of the IGF-IR blocking antibody (6), IGF-IR antisense oligonucleotide (7) or IGF-IR siRNA application (8). In the past decade, a family of low-molecular-weight compounds, the Tyrphostins, have been synthesized and identified as potent inhibitors of protein tyrosine kinases (PTKs). Various members of the Tyrphostin family have been observed to recognize the PTKs of various growth factor receptors, such as epidermal growth factor receptor (EGFR) and insulin-like growth factor receptor (IGF-IR), in a selective manner. Recently, IGF-IR tyrosine kinase inhibitors have been revealed to have antitumor effects, and these effects have already been demonstrated in HCC (9), colorectal cancer (10) and neuroendocrine gastrointestinal tumors (11).

In recent years, several studies have revealed that Tyrphostin AG1024, one tyrosine kinase inhibitor specifically targeting the IGF-I receptor, has antiproliferative effects in several breast cancer and leukemia cell lines, and exerted an antiproliferative effect, inducing apoptosis $(12,13)$. However, data regarding HCCs are scarce. The aim of this study was to examine the potential therapeutic effect of Tyrphostin AG 1024 in HCC. The results demonstrated that AG1024 potently inhibited the growth and induced apoptosis in human HCC cells.

\section{Materials and methods}

Cell Culture and drugs. The human HCC cell lines HepG2 and SMMC-7721 were cultured in DMEM medium containing $10 \%$ fetal bovine serum (FBS). The cells were maintained in a humidified atmosphere $\left(50 \mathrm{ml} / \mathrm{C} \mathrm{CO}_{2}\right)$ at $37^{\circ} \mathrm{C}$, and incubated in culture medium containing AG1024 (Sigma, USA). Stock solutions (in DMSO, stored at $-20^{\circ} \mathrm{C}$ ) were diluted to the final concentration in fresh media before each experiment. In all experiments, the final DMSO concentration did not exceed $0.2 \mathrm{ml} / 1$.

Flow cytometry. Cells were plated in a 6-well plate $(2 \mathrm{ml} /$ well) at a density of $5 \times 10^{5}$ cells $/ \mathrm{ml}$ and incubated overnight. 


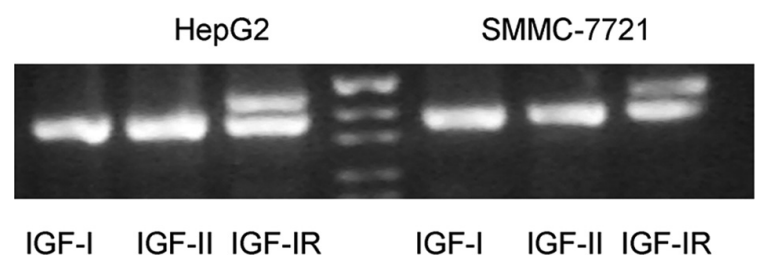

Figure 1: Expression of IGF-I, IGF-II, IGF-IR in Human HCC cell lines. mRNA expression of IGF-IR was detectable in both cell lines while expressions of IGF-I, IGF-II was not detectable.
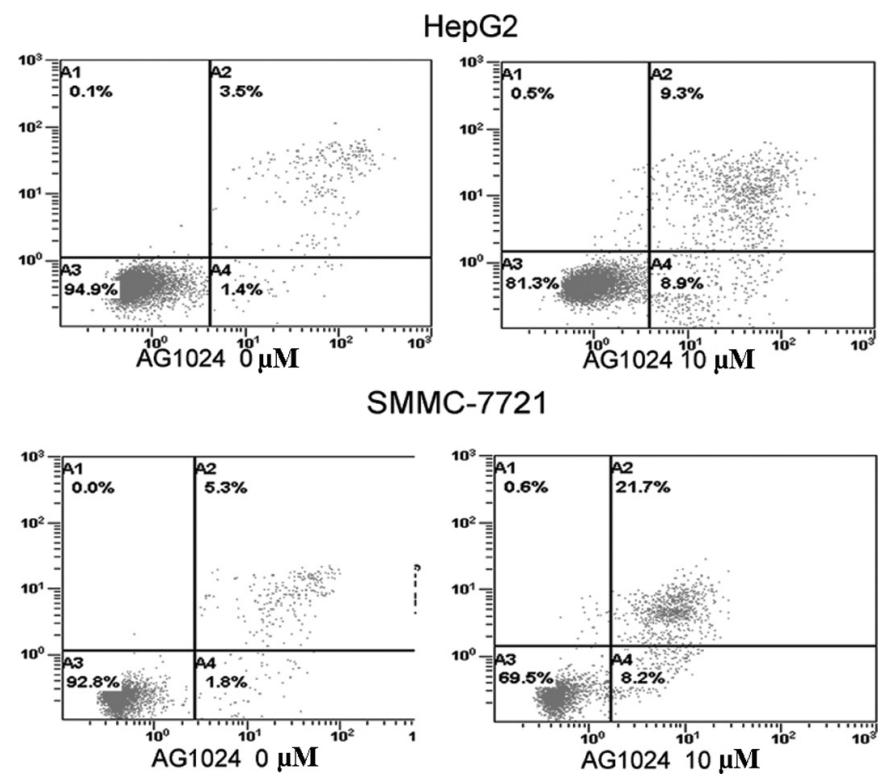

Figure 2: AG1024 induced apoptosis in HepG2 and SMMC-7721 cells. Cells treated with $10 \mu \mathrm{M}$ AG1024 in HepG2 and SMMC-7721 for $24 \mathrm{~h}$ as well as the negative control group were double-stained with Annexin V and PI and analyzed by flow cytometry. Gate setting distinguish between viable (bottom left), necrotic (top left), early apoptotic (bottom right) and late apoptotic (top right) cells.

AG1024 at the indicated concentrations was then added to each well, followed by incubation for $24 \mathrm{~h}$. The cells were harvested, washed twice with pre-chilled PBS, and resuspended in $1 \mathrm{X}$ binding buffer at a concentration of $1 \times 10^{6}$ cells $/ \mathrm{ml}$. The resulting solution (100 $\mu \mathrm{l}$ containing $1 \times 10^{5}$ cells) was mixed with $5 \mathrm{ml}$ of Annexin V-FITC and $5 \mathrm{ml}$ of propidium iodide (BD Biosciences, San Jose, CA, USA) according to the manufacturer's instructions. The mixture was gently vortexed and incubated in the dark at room temperature $\left(25^{\circ} \mathrm{C}\right)$ for $15 \mathrm{~min}$. Subsequently, a $1 \mathrm{X}$ dilution buffer $(400 \mu \mathrm{l})$ was added to each tube, and an analysis of cell apoptosis was performed within $1 \mathrm{~h}$ using the Beckman Coulter FC500 Flow Cytometry System with CXP Software (Beckman Coulter, Fullerton, CA, USA).

Cell invasion assay. The cell invasion assay was performed essentially as previously described $(14,15)$. This experiment employed two HCC cell lines. Briefly, a Transwell cell culture chamber (Millipore, Bedford, MA, USA) with a 6.5 -mm-diameter polycarbonate filter $(8-\mu \mathrm{m}$ pore size) was coated with Matrigel, dried, and reconstituted at $37^{\circ} \mathrm{C}$ with culture medium before use. The cells were divided into three groups: the control group, the AG1024 low concentration
HepG2

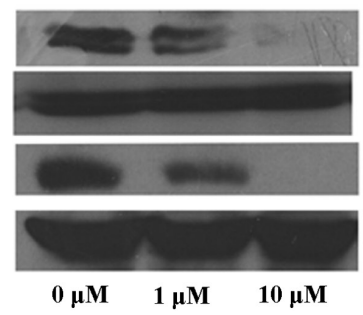

SMMC-7721

Figure 4: Effect of Tyrphostin AG1024 on the expression of phosphor-ERK and ERK. Cells were treated with various concentrations of Tyrphostin AG 1024. Cells were exposed to Tyrphostin AG 1024, lysed and immunoblotted for the phosphotyrosine-containing protein of $44 \mathrm{kD}$. As shown in Fig. 5 Phosphor-ERK was dose-dependently down-regulated by Tyrphostin AG 1024 , but the amount of ERK remained the same.

group, and the AG1024 high concentration group. The cells were added to the upper chamber at a density of $1 \times 10^{5}$ cells per chamber in culture medium containing 10\% FBS. After a $24 \mathrm{~h}$ incubation at $37^{\circ} \mathrm{C}$, the medium in the lower chamber was removed, fixed and stained. The number of cells that had migrated through the pores of the filter into the lower chamber was counted in five fields per chamber under a phase-contrast microscope (Leica DMLB2, Leica Microsystems AG, Wetzlar, Germany). Each invasion experiment was carried out in duplicate and repeated at least twice.

$R T-P C R$. Total RNA was isolated from the HCC HepG2 and SMMC-7721 cell lines grown under basal conditions using an RNA isolator kit (Tri Reagent, Sigma Chemical), and reversetranscribed. The samples were amplified for 3 cycles using specific primers for IGF-I, IGF-II, IGF-IR and GAPDH (as the housekeeping positive control gene). Briefly, an initial denaturing step at $95^{\circ} \mathrm{C}$ for 4 min was followed by a set number of cycles at $94^{\circ} \mathrm{C}$ for $10 \mathrm{sec}, 58^{\circ} \mathrm{C}$ for $10 \mathrm{sec}$, and $72^{\circ} \mathrm{C}$ for $15 \mathrm{sec}$. PCR products were separated on a $2 \% \mathrm{wt} / \mathrm{vol}$ agarose gel containing ethidium bromide, visualized by UV illumination, and scanned. Densitometry values were corrected to GAPDH.

Western blotting. Protein was extracted from cultured cells and subjected to Western blot analysis using specific antibodies against phospho-ERK protein, ERK protein (Cell Signaling Technology, CA, USA), and pro-caspase-3 (Santa Cruz Biotechnology, CA, USA). The cells were harvested and rinsed twice with PBS. Cell extracts were prepared with prechilled lysis buffer (50 nM Tris- $\mathrm{HCl}, 150 \mathrm{mM} \mathrm{NaCl}, 1 \%$ Triton $\mathrm{X}-100,0.5 \%$ deoxycholate, $1 \mathrm{mM}$ EDTA, $1 \mathrm{mM} \mathrm{Na} \mathrm{VO}_{4}$, $1 \mathrm{mM} \mathrm{NaF}, 2 \%$ cocktail) and cleared by centrifugation at $12,000 \mathrm{~g}$ for $15 \mathrm{~min}$ at $4^{\circ} \mathrm{C}$. The supernatant was collected and the total protein concentration was measured using the BCA assay kit (Sigma) according to the manufacturer's instructions. Cellular extract containing $30 \mu \mathrm{g}$ of total protein was separated by $12 \%$ SDS-polyacrylamide gel electrophoresis (SDS-PAGE), and the proteins were transferred electrophoretically onto a nitrocellulose membrane (Millipore). The membrane was then blocked with Tris-Buffered Saline and Tween-20 (TBST) (10 mM Tris-Cl, pH 7.4, $150 \mathrm{mM} \mathrm{NaCl}$, $0.1 \%$ Tween-20) containing $5 \% \mathrm{w} / \mathrm{v}$ non-fat dry milk, and incubated with primary antibody in TBST at $4^{\circ} \mathrm{C}$ overnight. 

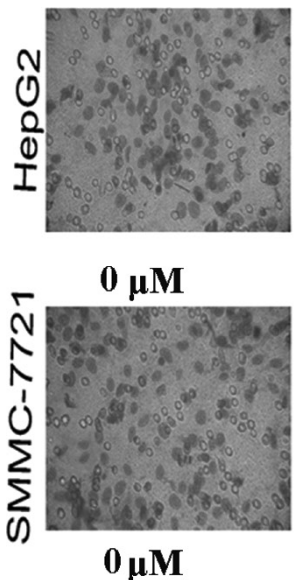

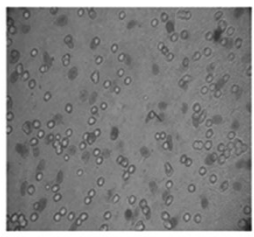

$1 \mu \mathbf{M}$

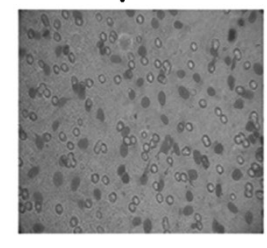

$1 \mu \mathbf{M}$

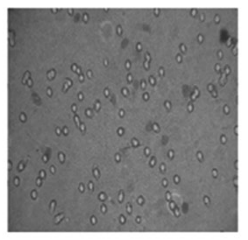

$10 \mu \mathrm{M}$

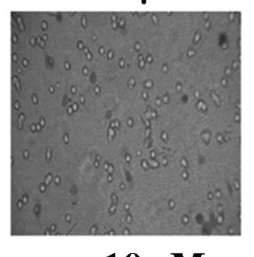

$10 \mu \mathrm{M}$

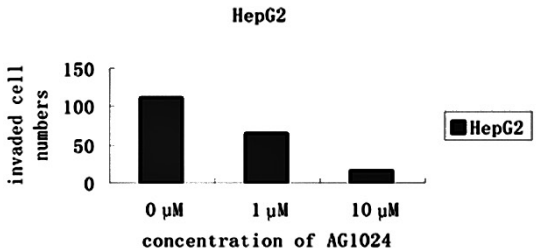

SMMC-7721

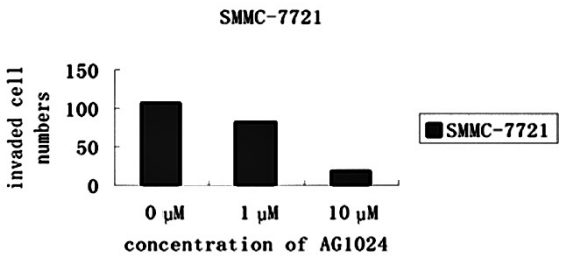

Figure 3: Effect of AG1024 on cell invasion. Transwell invasion assay was performed in two HCC cell lines with AG1024 and negative control. Cells were fixed, stained and counted at $24 \mathrm{~h}$. The cell numbers of the AG1024-treated groups were significantly lower than those of the control group ( $<<0.05$ ), which demonstrated that AG1024 decreased cell invasion dose-dependently.

The membrane was washed three times and hybridized with horseradish peroxidase (HRP)-conjugated secondary antibody (dilution, 1:2000) for $2 \mathrm{~h}$ at room temperature. After washing three times for $10 \mathrm{~min}$ each with $15 \mathrm{ml}$ TBST, protein bands specific to the antibody were visualized by enhanced chemiluminescence (Amersham Pharmacia Biotech, Piscataway, NJ, USA) associated fluorography.

Statistical analysis. Results are expressed as the means \pm SD. The data were compared using the Student's t-test for paired samples. $\mathrm{P}<0.05$ was considered statistically significant.

\section{Results}

Changes in IGF mRNA expression in human HCC cell lines. Expression of IGF-IR was investigated in human HCC cells. Messenger ribonucleic acid (mRNA) expression of IGF-IR was detectable in both cell lines, while expression of IGF-I and IGF-II was not detectable (Fig. 1).

Apoptosis induced by Tyrphostin AG 1024. To explore the apoptotic response induced by Tyrphostin AG1024, HepG2 and SMMC-7721 cells were exposed to Tyrphostin AG1024 at a concentration of $10 \mathrm{nM}$. As shown in Fig. 2, the percentages of apoptotic cells were 18.2 and $29.9 \%$, respectively, in cells exposed to Tyrphostin AG1024. This was statistically significant compared to the control group, in which the percentages of apoptotic cells were 4.9 and $7.1 \%(\mathrm{P}<0.05)$.

Effect of AG1024 on HCC cell invasion. The effects of AG1024 on the invasion ability of HepG2 and SMMC-7721 cells in vitro were examined using an invasion assay system with reconstituted Matrigel membrane. Experiments were repeated three times. The number of cells that had migrated through the filter and into the lower chamber was counted and compared between groups. HepG2 cell numbers in the groups treated with $1 \mu \mathrm{m}$ and $10 \mu \mathrm{M}$ AG1024 were $65.6 \pm 14.6$ and $15.0 \pm 6$, respectively, which was significantly lower than the cell numbers in the control group $(112.0 \pm 9.20, \mathrm{P}<0.05)$ (Fig. 4). SMMC-7721 cell numbers in the groups treated

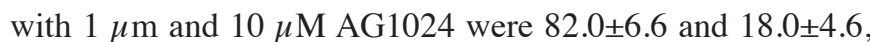
respectively, which was significantly lower than in the control group $(107.7 \pm 10.0, \mathrm{P}<0.05)$ (Fig. 3). These data indicated that AG1024 treatment significantly inhibited the cell invasion of the two HCC cell lines through the Matrigel basement membrane.

Dose-dependent decrease in phosphor-ERK expression after Tyrphostin AG 1024 treatment. To measure the amount of phosphor-ERK, cells were exposed to Tyrphostin AG 1024, lysed and immunoblotted for phosphotyrosine-containing protein of $44 \mathrm{kD}$. As shown in Fig. 4, phosphor-ERK was dose-dependently down-regulated by Tyrphostin AG 1024, while the amount of ERK remained the same.

\section{Discussion}

HCC remains a pressing medical concern. Recently, the incidence of HCC has increased dramatically in the US, Asia and Europe. Nearly $55 \%$ of new cases of HCC occur in China (16). Recent studies have revealed that PTK inhibitors exert an anticancer effect in several human malignant tumors, such as human breast cancer (12) and leukemia (13). Tyrphostin AG 1024 is a suitable candidate for PTK inhibition. Previous studies have revealed that IGF-IR-specific mRNA is detectable in the human HCC cell lines PLC73 and HepG2 (17). This is in agreement with the results of the present study (Fig. 1).

Here, we investigated the ability of tyrphostin AG 1024, an IGF-IR inhibitor, to prohibit proliferation, induce apoptosis and decrease invasion. The results indicate that the inactivation of IGF-I function may be essential for the induction of apoptosis. First, IGF-I and IGF-II were revealed to play an essential role in tumorigenesis, protecting tumor cells from apoptosis $(18,19,20)$. Both are capable of activating the downstream signaling cascade by binding type I insulin-like growth factor receptor. Second, proliferation and apoptosis were inhibited by blockage of the IGF-IR signaling pathway. Tyrphostin AG1024 was observed to significantly promote apoptosis in the HCC cells in a dose-dependent manner (Fig. 2), and to inhibit the invasion ability of cancer cells (Fig. 3). 
To date, the effect of IGF-IR inhibitor on HCC cell lines has yet to be examined. IGF-IR includes at least three survival signaling pathways that are responsible for protecting cancer cells from apoptosis. These are the PI-3K/AKT, MAPK/ERK and 14-3-3 signaling pathways. The 14-3-3 signaling pathway results in the mitochondrial translocation of Raf-1 (21). Blocking two of these pathways is essential to diminish the capacity of IGF-IR to protect cells from apoptosis (22). Thus, we hypothesized that blockade of these two survival pathways by AG1024 would successfully inhibit the growth of the HCC cell line. The results indicated that exposure to the IGF-IR inhibitor Tyrphostin AG1024 induced a marked decrease in the expression of phosphor-ERK (Fig. 4). Similar results were reported by Michael et al, who found that apoptosis was induced in cancer cells by inhibition of the MAPK-ERK pathway $(11,22)$.

Apoptosis is a process of programmed cell death that involves a great deal of interaction between anti- and proapoptotic cytokines. The present study aimed to explore the mechanisms of AG1024-induced apoptosis in HCC cell lines and the expression of certain apoptosis-related factors. It is widely accepted that mitochondria play a crucial role in apoptosis, and that the caspase cascade plays a crucial role in the process of apoptosis (23). Once activated, caspase-9 disassociates from the complex and becomes available to cleave and activate downstream caspases, such as caspase-3. Caspases involved in the execution of apoptosis are present in living cells as inactive zymogens, which are activated through intracellular caspase cascades. There are two relatively wellcharacterized caspase cascades: one initiated by the activation of cell-surface death receptors, such as Fas and tissue necrosis factor, leading to caspase- 8 activation, which is in turn responsible for cleaving and activating downstream caspases such as caspase-3; the other is triggered by cytochrome c released from the mitochondria, which promotes the activation of caspase-9 (24).

In conclusion, the data suggest that the AG1024-mediated apoptosis of HCC cells is caspase-3-dependent. The IGFR-TK inhibitor AG1024 potently inhibited the growth of human HCC cells and induced apoptosis. Thus, inhibition of IGFRsignaling by AG1024 may be a promising targeted anticancer strategy for HCC. Further studies in vivo are warranted.

\section{Acknowledgements}

This work was supported by a grant from the Science and Technology Department of Zhejiang province (no. 2005C23027).

\section{Reference}

1. Michalopoulos GK and DeFrances MC: Liver regeneration. Science 276: 60-66, 1997.

2. Fausto N, Laird AD, and Webber EM: Liver regeneration. 2. Role of growth factors and cytokines in hepatic regeneration. Faseb J 9: 1527-1536, 1995.

3. Pietrzkowski Z, Mulholland G, Gomella L, et al: Inhibition of growth of prostatic cancer cell lines by peptide analogues of insulin-like growth factor 1. Cancer Res 53: 1102-1106, 1993.
4. Scrimgeour AG, Blakesley VA, Stannard BS, and LeRoith D: Mitogen-activated protein kinase and phosphatidylinositol 3-kinase pathways are not sufficient for insulin-like growth factor I-induced mitogenesis and tumorigenesis. Endocrinology 138: 2552-2558, 1997.

5. Sell C, Baserga R and Rubin R: Insulin-like growth factor I (IGF-I) and the IGF-I receptor prevent etoposide-induced apoptosis. Cancer Res 55: 303-306, 1995.

6. Scotlandi K, Benini S, Nanni P, et al: Blockage of insulin-like growth factor-I receptor inhibits the growth of Ewing's sarcoma in athymic mice. Cancer Res 58: 4127-4131, 1998.

7. Shapiro DN, Jones BG, Shapiro LH, et al: Antisense-mediated reduction in insulin-like growth factor-I receptor expression suppresses the malignant phenotype of a human alveolar rhabdomyosarcoma. J Clin Invest 94: 1235-1242, 1994.

8. Salisbury AJ and Macaulay VM: Development of molecular agents for IGF receptor targeting. Horm Metab Res 35: 843-849, 2003.

9. Nardone G, Romano M, Calabro A, et al: Activation of fetal promoters of insulinlike growth factors II gene in hepatitis $\mathrm{C}$ virus-related chronic hepatitis, cirrhosis, and hepatocellular carcinoma. Hepatology 23: 1304-1312, 1996.

10. Hopfner M, Sutter AP, Huether A, et al: Tyrosine kinase of insulinlike growth factor receptor as target for novel treatment and prevention strategies of colorectal cancer. World J Gastroenterol 12: $5635-5643,2006$

11. Hopfner M, Baradari V, Huether A, et al: The insulin-like growth factor receptor 1 is a promising target for novel treatment approaches in neuroendocrine gastrointestinal tumours. Endocr Relat Cancer 13: 135-149, 2006.

12. Camiran A, Zakikhani M, Young F, et al: Inhibition of insulin-like growth factor-1 receptor signaling enhances growthinhibitory and proapoptotic effects of gefitinib (Iressa) in human breast cancer cells. Breast Cancer Res 7: R570-R579, 2005.

13. Deutsch E, Maggiorella L, Wen B, et al: Tyrosine kinase inhibitor AG1024 exerts antileukaemic effects on STI571-resistant Bcr-Abl expressing cells and decreases AKT phosphorylation. Br J Cancer 91: 1735-1741, 2004.

14. Liu B, Staren E, Iwamura T, et al: Effects of taxotere on invasive potential and multidrug resistance phenotype in pancreatic carcinoma cell line SUIT-2. World J Gastroenterol 7: 143-148, 2001.

15. Wolf WC, Evans DM, Chao L, et al: A synthetic tissue kallikrein inhibitor suppresses cancer cell invasiveness. Am J Pathol 159: 1797-1805, 2001.

16. Parkin DM, Bray F, Ferlay J, et al: Global cancer statistics, 2002. CA Cancer J Clin 55: 74-108, 2005.

17. Verspohl EJ, Maddux BA and Goldfine ID: Insulin and insulinlike growth factor I regulate the same biological functions in HEP-G2 cells via their own specific receptors. J Clin Endocrinol Metab 67: 169-174, 1988.

18. Humbel RE: Insulin-like growth factors I and II. Eur J Biochem 190: 445-462, 1990.

19. Macaulay VM: Insulin-like growth factors and cancer. Br J Cancer 65: 311-320, 1992.

20. Baserga R: The insulin-like growth factor I receptor: a key to tumor growth? Cancer Res 55: 249-252, 1995.

21. Thomas D, Guthridge M, Woodcock J, et al: 14-3-3 protein signaling in development and growth factor responses. Curr Top Dev Biol 67: 285-303, 2005.

22. Hopfner M, Huether A, Sutter AP, et al: Blockade of IGF-I receptor tyrosine kinase has antineoplastic effects in hepatocellular carcinoma cells. Biochem Pharmacol 71: 1435-1448, 2006.

23. Du C, Fang M, Li Y, et al: Smac, a mitochondrial protein that promotes cytochrome c-dependent caspase activation by eliminating IAP inhibition. Cell 102: 33-42, 2000.

24. Boldin MP, Goncharov TM, Goltsev YV, et al: Involvement of $\mathrm{MACH}$, a novel MORT1/FADD-interacting protease, in Fas/ APO-1- and TNF receptor-induced cell death. Cell 85: 803-815, 1996. 